\title{
- O Monitoramento das Prioridades (1) de Governo no Ministério do Planejamento

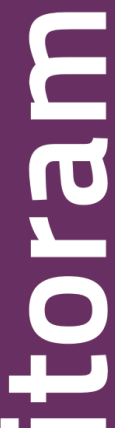

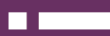
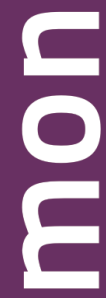

1 Este texto reflete opiniões pessoais dos autores, e não necessariamente das instituições citadas.

Lucas Vieira Abraão Maia² Marcos de Souza e Silva ${ }^{3}$ Vivian Montijo Salviano ${ }^{4}$

2 Secretaria de Planejamento e Investimentos Estratégicos do Ministério do Planejamento, Orçamento e Gestão.

3 Secretaria de Planejamento e Investimentos Estratégicos do Ministério do Planejamento, Orçamento e Gestão.

4 Secretaria de Planejamento e Investimentos Estratégicos do Ministério do Planejamento, Orçamento e Gestão. 


\section{Resumo}

O MONITORAMENTO DAS PRIORIDADES DE GOVERNO É UMA DAS OUUATRO DIMENSÕES DA ESTRATÉGIA DE MONITORAMENTO DO PPA 2012-2015 DO GOVERNO FEDERAL. O TEXTO TRAZ UM BREVE POSICIONAMENTO HISTÓRICO DA PRÁTICA DO PLANEJAMENTO DE POLÍTICAS PÚBLICAS NO BRASIL ATÉ O CENÁRIO ATUAL, E RELACIONA ESSA TRAJETÓRIA COM AS MUDANÇAS INSTITUCIONAIS OCORRIDAS EM VIRTUDE DAS ESCOLHAS DEMOCRÁTICAS RECENTES. SEGUE-SE UMA DESCRIÇÃO OBJETIVA DOS SISTEMAS DE MONITOAbstract RAMENTO DE AGENDAS PRIORITÁRIAS IMPLANTADOS PELO GOVERNO FEDERAL NA ÚLTIMA DÉCADA, CHEGANDO FINALMENTE AO MONITORAMENTO DAS PRIORIDADES DA PRESIDÊNCIA E SEU TRATAMENTO DENTRO DO Ministério do Planejamento, Orçamento e Gestão. Por FIM, JUNTAMENTE COM CRÍTICAS AOS PROCESSOS DE GESTÃO EM VIGOR, ESTABELECEM-SE OS DESAFIOS PARA A MELHORIA DAS PRÁTICAS ADMINISTRATIVAS OQUE TÊM IMPACTOS DIRETOS NA OQUALIDADE DAS ENTREGAS DE BENS E SERVIÇOS PARA A SOCIEDADE.

\begin{abstract}
Monitoring Presidential PRIORITIES IS ONE OF FOUR DIMENSIONS OF BRAZILIAN FEDERAL GOVERNMENT'S MONITORING STRATEGY FOR THE Multiannual Plan 2012-2015. The article briefly REVIEWS THE HISTORY OF MONITORING PRACTICES IN BRAZIL LEADING TO THE PRESENT MOMENT, AND RELATES ITS TRAJECTORY TO INSTITUTIONAL CHANGES DUE TO DEMOCRATIC CHOICES IN RECENT YEARS. IT ALSO DESCRIBES THE MONITORING SYSTEMS FOR THE PRESIDENTIAL PRIORITIES CREATED OVER THE LAST DECADE, PAYING SPECIAL ATTENTION TO THE CURRENT STAGE OF THE MONITORING STRATEGY. FINALLY, BASED ON SOME OF THE CRITICISMS RAISED UPON THE MANAGEMENT PROCESS OF PUBLIC POLICIES SOME CHALLENGES ARE HIGHLIGHTED AND LINKED WITH THE NECESSITY OF IMPROVING PRACTICES TO DELIVER BETTER SERVICES TO SOCIETY
\end{abstract}

\section{PALAVRAS-CHAVE:}

Políticas públicas; Planejamento; Monitoramento; Prioridade de governo

Revista Brasileira de Monitoramento e Avaliação | Número 5 | Janeiro-Junho de 2013 


\section{Introdução}

O momento histórico brasileiro atual deve ser visto como peculiar na trajetória nacional. Pela primeira vez o país congrega, por um período que já se aproxima de duas décadas, estabilidade econômica, desenvolvimento (ainda que com diferentes matizes ideológicos) e manutenção de um ambiente democrático. De forma mais significativa, a última década viu o Brasil eleger como diretriz política o retorno do Estado à posição de ator central na condução do desenvolvimento econômico e social. A máquina pública novamente passou a operar como indutora e promotora do bem-estar, com o aumento de sua participação nas atividades econômicas e, principalmente, com a busca pela implantação de um Estado de Bem-Estar Social, baseado no aumento das oportunidades de inserção no mercado de trabalho, na política de assistência social agora constitucionalmente reconhecida como direito, e não mais como atribuição filantrópica -, no combate às desigualdades e na superação da extrema pobreza.

Dessa maneira, a pressão pela reestruturação de um Estado capaz de planejar e implementar políticas públicas passou a ser cada vez mais presente, o que desencadeou um processo de reformulação das instituições, que vêm se tornando cada vez mais complexas em suas estruturas e suas atribuições ${ }^{5}$. Viu-se, paulatinamente, a retomada da função planejamento no interior da administração pública, com a recuperação da capacidade tanto em termos de recursos humanos quanto em aspectos do modo de operar o Estado. Nesse ponto, tem-se como referência a Constituição de 1988 , que definiu em seu texto os principais instrumentos formais de planejamento, quais sejam, o Plano Plurianual (PPA), a Lei de Diretrizes Orçamentárias (LDO) e a Lei Orçamentária Anual (LOA). Tais peças legais, ainda que inicialmente formais, começaram a delinear o modus operandi da administração pública nacional no que diz respeito ao planejamento.

Desde então, juntamente com a criação desses instrumentos, trava-se uma busca por modelos de monitoramento que qualifiquem a ação estatal, permitindo-a entregar os resultados pretendidos à população. Durante esse período, no entanto, foram sendo desveladas limitações referentes aos modelos empregados, principalmente após a decisão política de orientar o Estado brasileiro para fazê-lo. Os modelos até então desenvolvidos não atendiam às necessidades de um Estado voltado para as transformações necessárias para garantir direitos constitucionais ou legalmente atribuídos à população.

Ficava evidente o choque entre a nova racionalidade política - advinda da emergência de novo protagonismo estatal e, portanto, da função planejamento - e a racionalidade burocrática predominante nas instituições, afeitas à inércia e a outros vícios. A divergência colocava em polos opostos a necessidade de entregas efetivas de bens e serviços à população e o conhecido apego aos meios e processos, característica marcante da gestão pública brasileira.

Essas fragilidades puseram em xeque os mecanismos à disposição do poder público para dirigir o País, e, como resultado, foram sendo criadas alternativas que possibilitaram à ad- 
ministração pública colocar em marcha seu projeto político. Essa escolha envolveu a criação de novas institucionalidades, que passaram a reger o planejamento, a implementação e o monitoramento das políticas públicas, sempre orientando os esforços do governo para a efetivação de suas escolhas políticas.

Quanto ao monitoramento, em particular, passaram a coexistir arranjos de monitoramento amplos, incidentes sobre todas as políticas do Governo Federal (modelo de monitoramento do Plano Plurianual 20012 - 2015, por ex.); e específicos, destinados a um grupo de agendas eleitas como mais relevantes pelo governante eleito (Acompanhamento de Temas Prioritários do Governo Dilma, por ex.). Explicaremos mais adiante as razões para possíveis sobreposições entre os objetos desses dois monitoramentos, residentes em suas diferentes bases de legitimação e operação.

Iniciaremos o texto desenvolvendo aspectos que ajudam na compreensão da (co)existência dos diferentes modelos de monitoramento. Em seguida, nos dedicamos às razões para a instituição do monitoramento específico.

\section{O que se entende por monitoramento de políticas públicas}

O monitoramento de políticas públicas encontra lugar de destaque dentro da função planejamento quando se considera que seu objetivo é, fundamentalmente, o aprendizado sobre as ações do governo e seus impactos na sociedade, tanto no campo técnico-burocrático quanto no político, conferindo a devida relevância para a intersetorialidade que as permeia e marca ${ }^{6}$. Esse entendimento traz o monitoramento para posição central na aquisição de conhecimento necessário para agir em prol da implementação de políticas e para o aumento de entregas efetivas de bens e serviços à população. Esse processo requer a qualificação da força de trabalho que impacta diretamente o perfil dos servidores públicos, conduzindo à qualificação de todos os envolvidos no aprofundamento da compreensão relativa a cada política e à complexidade relacionada ao processo de aquisição de informações relevantes a respeito delas.

Pretende-se contrapor o entendimento de políticas públicas como fenômeno sequen- 
cial $^{7}$, que se materializa na teoria do ciclo da política pública ${ }^{8}$, a uma visão que considera o aprofundamento das relações institucionais presentes em cada agenda governamental como fundamental para a produção de informações relevantes para a tomada de decisões. Propõe-se um trabalho contínuo, cumulativo e coletivo para que se obtenham esses conhecimentos densos e aprofundados, tanto da realidade como da formulação, implementação e gestão cotidianas das políticas públicas, resultando em informações harmonizadas e indicadores úteis ao gerenciamento tempestivo das ações de governo9. ${ }^{10}$

Torna-se crucial a construção de uma metodologia para escapar da racionalidade do modelo hegemônico praticado nas Ciências Sociais, baseado na lógica determinista e cartesiana advinda da revolução científica do séc. XVI ${ }^{11}$ e fortalecida pela estruturação de um sistema de educação e pesquisa coordenado pela racionalidade do resultado mensurável e que necessariamente agregue valor para o gestor do sistema ${ }^{12}$. Essa nova metodologia deverá disponibilizar, para os ocupantes de posições estratégicas, dados relevantes e estruturados sobre as agendas de governo.

Dessa forma, o monitoramento sugerido pressupõe atualizações frequentes e oportunas do conhecimento atinente à agenda monitorada, com o deslocamento da lógica da demanda por informações fragmentadas para uma nova premissa que privilegie sua oferta a partir do acúmulo, tratamento e disponibilização de informações densas e estruturadas. A ideia é qualificar o subsídio ao processo de tomada de decisão com vistas a ampliar as ca- pacidades institucionais do Estado como promotor do desenvolvimento e do bem comum, balizando as informações a partir de fundamentos republicanos e democráticos.

Nesse caminho, algumas armadilhas devem ser identificadas e evitadas, para que não se perca de vista seu objetivo principal, que consiste no apoio à implementação das políticas. A linguagem utilizada precisa ser clara, de fácil compreensão, sem o vício técnico gerencialista ${ }^{13}$. A implementação deve ser entendida como etapa rica em insumos para a constante adequação da política, ficando afastada sua conceituação como mera execução de ideias concebidas em ambiente de suposto domínio pleno da realidade. O cenário é ainda mais complexo à medida que o desafio de aglutinar e interpretar informações seja realizado em contexto que nem sempre favorece o compartilhamento de informações. Devem-se levar em conta os constrangimentos provenientes da divulgação de dados desfavoráveis ao alcance de metas estabelecidas. Exibir fraquezas não costuma ser prática frequente nos processos de governo.

Portanto, o entendimento ora adotado sobre monitoramento é o de um processo técnico-político que deve municiar o Estado, nas figuras dos responsáveis pela implementação das políticas públicas, de informações úteis para o aperfeiçoamento contínuo da atuação do poder público. Dentro dessa perspectiva, surgem alternativas para os sistemas tradicionais, tais como: o Sistema de Monitoramento das Metas Presidenciais (SMMP), o Sistema de Monitoramento do Plano de Aceleração do Crescimento (PAC) e o Monitoramento das Prioridades da Presidência da República. 


\section{Tensão entre as}

\section{racionalidades política e burocrática no monitoramento}

Não é objeto desse trabalho uma revisão pormenorizada do planejamento no Brasil, mas algumas breves reflexões devem ser feitas para que se compreenda melhor o surgimento do Monitoramento de Prioridades da Presidência no contexto atual do Estado.

Como foi abordado anteriormente, a atividade de planejamento renasceu, a princípio formalmente, no Estado brasileiro, na década de 1990, e ganhou importância de forma consistente com o aumento da participação do governo na vida do País. Durante o período de declínio e no início de seu renascimento (décadas de 1980 e 1990), o planejamento não contava com mecanismos adequados de monitoramento das políticas públicas, ficando a ênfase nas análises da execução física e financeira do orçamento, com pouca ou nenhuma atenção voltada para os impactos da ação de governo e para os arranjos institucionais formados em torno das agendas que desvelavam as escolhas políticas de cada período.

Diante desse cenário de pouca efetividade, o Governo Federal instituiu práticas alternativas de gestão, que operavam paralelamente às legalmente estabelecidas, mas que atendiam às demandas dos decisores por informações relevantes e tempestivas sobre agendas prioritárias. As experiências mais relevantes foram o Sistema de Metas Presidenciais, durante o primeiro governo Lula; o Monitoramento do PAC, a partir de 2007; e, mais recentemente, o Monitoramento das Prioridades da Presidência, já no governo Dilma.

Essas iniciativas indicavam que a racionalidade política - visão do governo eleito acerca da lógica de funcionamento da máquina esta-

7 MULLER, P. SUREL, Y., 2002.

8 SOUZA, C., 2006.

9 PEREIRA, P.A.P., 2011, PRESSMAN, J.L. WILDAVSKY, A., 1998.

10 Para aprofundamento dos termos utilizados acima, ver texto complementar a este, contendo a visão geral da estratégia de monitoramento do PPA 2012-2015.

11 SANTOS, B.S., 1998.

12 SCHNEIDER, A.L., 2006.

13 MORETTI, B., 2012.

Revista Brasileira de Monitoramento e Avaliação | Número 5 | Janeiro-Junho de 2013 
tal - entrava em conflito com a racionalidade burocrática - visão estabelecida na máquina estatal sobre a lógica de seu próprio funcionamento. Enquanto a primeira sentia o peso dos embargos institucionais e burocráticos na limitação de sua capacidade de entrega de resultados à população, a segunda buscava se adaptar apenas lentamente ao novo cenário.

Isso significa que essas novas instituições foram idealizadas, ou ainda, foram implementadas, para suprir lacunas na oferta de conhecimento sobre a real condição de execução das políticas, bem como para enfrentar as condições institucionais mais bem adaptadas à função controle que à efetividade das ações de governo. Essa nova visão sobre como deve ser o acompanhamento das atividades de governo revelou inadequações do modelo vigente, e deixou claro que para que o governo alcançasse seus objetivos não poderia se fundamentar nas estruturas burocráticas tradicionais que exerciam essas funções. Começava, assim, uma nova perspectiva sobre o monitoramento das agendas de governo, com repercussão no entendimento diferenciado sobre o próprio conceito por trás da atuação dos agentes públicos.

\section{Monitoramento específico}

Ao assumir o poder, qualquer Presidente da República traz consigo seu Plano de Governo, o qual espera traduzir, por ação das políticas públicas, as necessidades de transformação da realidade embutidas na ideologia legitimada pelo voto popular. Consequentemente, a agenda governamental trará ações conside- radas prioritárias para se alcançar os objetivos que espelham as transformações propostas no Plano de Governo.

Essas intervenções prioritárias, quando postas em execução, enfrentarão obstáculos políticos, institucionais e técnico-burocráticos, tais como quaisquer outras ações governamentais. Ocorre que, por definição, as prioridades de governo carregam expectativas mais representativas do sucesso ou fracasso da gestão presidencial eleita. Por esse motivo, projetando-se as dificuldades em distribuir esforços iguais sobre todas as políticas públicas, é razoável que o governante eleito escolha um conjunto de ações e dedique a elas um aparato especial para acompanhamento, coordenação e solução de empecilhos.

A estruturação de um sistema de alta direção é sempre necessária quando da instalação do novo governo para auxiliar e assessorar a atuação do Presidente da República nos diversos campos e domínios por onde transita, e para dotar o processo decisório de governo de condições de segurança e direcionalidade ${ }^{14}$.

Dessa maneira, a existência de programas prioritários já é condição suficiente para explicar a necessidade de um mecanismo de monitoramento especialmente desenhado para atendê-los. Em qualquer governo ocorre certa hierarquização de políticas, e seria ingênuo supor que agendas com status diferenciados dentro da cúpula de governo não recebam tratamento prioritário em níveis orçamentários, normativos, executórios e de acompanhamento. 
A preocupação de um monitoramento específico é com o imediato alcance de resultados dentro do ciclo de mandato do governante. 0 acompanhamento, portanto, ampara-se em soluções cotidianas de gestão, quase sempre incidentes sobre entraves à execução físico-financeira de suas metas. $O$ governo detecta uma ação cuja execução orçamentária está baixa (uma obra embargada por problemas ambientais, por ex.) e empreende esforços para destravá-la (capacita atores envolvidos para obtenção da licença ambiental, por ex.). Não há, propriamente, avaliação de resultados (eficiência, efetividade, desempenho financeiro, qualidade de serviços, benefícios à sociedade), restringindo-se ao estágio de alcance das metas possíveis com o aparato institucional disponível.

É de se esperar, portanto, que a urgência na implementação de soluções para os entraves de execução e a natureza de curto prazo dessas soluções componham um sistema de acompanhamento menos capaz de oferecer aprendizado amplo aos atores envolvidos. Já que, na seção 2, reforçamos tanto a importância da construção e difusão do conhecimento sobre a realidade social e os arranjos de políticas necessários para transformá-la, não seria contraditório, portanto, identificar eficácia num arranjo de monitoramento específico? A resposta é não.
Um sistema assim não se justifica apenas pelo argumento político da existência de agendas prioritárias; ele é capaz de trazer eficácia à ação governamental. A força política com que um monitoramento desse tipo opera, dada a relevância de seu objeto para o governo, muitas vezes, cria condições para a implementação na administração pública. Em uma próxima seção, mostraremos que o PAC, por exemplo, conseguiu estabelecer rotinas eficazes para o monitoramento de suas ações a partir da validação de uma institucionalidade paralela àquele padrão, ao envolver forte coordenação de atores, regime de contratação próprio e proteção frente aos contingenciamentos orçamentários.

Portanto, desde que tenham focos ou objetos distintos, é aceitável que coexistam, simultaneamente, na mesma esfera de governo, diferentes estruturas de monitoramento de políticas. Em um fronte, o Monitoramento de Prioridades, legitimado nas prioridades do governante eleito, empreende esforços mais imediatos para entregar à sociedade os benefícios divulgados na campanha eleitoral; em outro, o desenvolvimento de uma vertente de monitoramento que, menos sujeita a pressões cotidianas, buscaria mapear déficits estruturantes da rede de implementação das políticas públicas, associados a capacidades organizacionais e processos institucionais de 
cada órgão envolvido. Esse conhecimento seria utilizado para, entre outros propósitos, reduzir assimetrias informacionais entre os atores envolvidos na política e promover uma cultura de aprendizado na administração pública.

Espera-se que, na medida do possível, todas as dimensões de monitoramento coexistentes na administração pública nutram-se de informações umas das outras, formando uma grande rede de geração/troca/aproveitamento de conhecimento sobre a política e evitando sobreposição de trabalho, principalmente das instâncias produtoras ou fornecedoras de informações primárias.

Nas próximas subseções, daremos exemplos de experiências governamentais com monitoramento específico. Após, dedicaremos uma seção mais longa ao Monitoramento de Prioridades da Presidenta Dilma.

\subsection{A EXPERIÊNCIA COM O SISTEMA DE MONITORAMENTO DAS METAS PRESIDENCIAIS}

Retomando as experiências recentes do governo brasileiro com recortes prioritários, tivemos, no segundo semestre de 2004, a implementação do Sistema de Monitoramento de Metas Presidenciais (SMMP), na gestão Lula. Na origem desse Sistema está a constatação, feita pelo governo eleito em 2002, da enorme desproporção entre os recursos governamentais existentes e as enormes ex- pectativas sociais geradas no processo eleitoral ${ }^{15}$. A proposta, então, era estabelecer um regime diferenciado de acompanhamento e de coordenação das ações envolvidas em cerca de 100 metas governamentais (número variável), tidas como prioritárias para o alcance dos objetivos de governo.

O processo de definição das Metas Presidenciais foi articulado por um Grupo Coordenador composto pela Assessoria Especial do Presidente - incorporada à Casa Civil em julho/2004, originando a Subchefia de Articulação e Monitoramento (SAM) -, pela Subchefia de Acompanhamento da Ação Governamental (SAG/CC) e pela Secretaria de Planejamento e Investimentos Estratégicos (SPI), do Ministério do Planejamento, Orçamento e Gestão (MPOG). A escolha das prioridades foi pautada por aquelas ações estratégicas que envolvessem um grande número de ministérios e que fossem capazes de gerar emprego e renda (elemento qualitativo do Sistema) com distribuição territorial equilibrada (regionalização).

Encabeçado pela SAM/CC, o Sistema reunia os atores envolvidos no alcance da meta num fluxo de informação constituído por: levantamento de resultados e da situação da meta (servidores de ministérios setoriais); validação e complementação de dados (monitores parceiros - técnicos da SPI/MP e da própria Casa Civil); e tratamento e análise das informações recebidas, bem como sugestão de encaminhamentos dos problemas e/ou oportunidades levantadas (monitores SAM). 
O fluxo acima culminava na confecção, pela SAM, do Relatório de Situação de Metas e do Relatório de Encaminhamentos, a partir dos quais a alta direção do governo (Ministro-Chefe da Casa Civil e o próprio Presidente) tomava decisões para solução dos problemas levantados, com destaque para a coordenação dos atores e para a provisão de recursos. O processo ancorava-se no Sistema de Informações Governamentais (SIGOV).

O Ministério do Planejamento, portanto, inseria-se nas rotinas desse monitoramento como instância de análise crítica da informação proveniente do ministério setorial. Embora também pudesse propor encaminhamentos, a participação da SPI, na prática, serviu principalmente para validar o preenchimento setorial.

O SMMP foi criado durante a vigência do Plano Plurianual 2004-2007, que também previa uma estrutura para monitoramento e avaliação das ações nele contidas. As necessidades de celeridade, dinâmica na troca de informações e até mesmo de recortes diferenciados de políticas, porém, tornavam o modelo de monitoramento do PPA e seu Sistema de Informações Gerenciais e de Planejamento (SIGPLAN) pouco úteis às decisões estratégicas do governo.

\subsection{A EXPERIÊNCIA COM O MONITORAMENTO DO PAC}

Posteriormente, com a reeleição do Presidente e sob forte pressão para criação de um plano que impactasse positivamente o crescimento do País, instituiu-se, em janeiro de 2007, o Programa de Aceleração do Crescimento (PAC). Dessa forma, as prioridades anteriormente vigentes passaram a ser substituídas pelas metas do PAC, com a criação de um novo sistema pelo Serviço Federal de Processamento de Dados (Serpro) e pela SPI: o Sistema de Monitoramento do PAC (Sispac). As metas presidenciais passaram a ser compreendidas como as metas do PAC.

Essa é uma boa ilustração das motivações para a criação de um regime de acompanhamento diferenciado de políticas públicas: os moldes genéricos, aqui representados pelo modelo de gestão do PPA, não se mostravam compatíveis com as necessidades demandadas pelas instâncias superiores de governo, de detectar/solucionar, em curto prazo, os entraves à execução dos grandes empreendimentos de infraestrutura do PAC.

Mais do que um caminho alternativo para o monitoramento, o PAC instituiu um novo modelo de implementação de políticas públicas no Bra- 
sil. Criou-se um "sistema fora do sistema", que operava à margem das limitações impostas pela excessiva morosidade dos processos até então instituídos. O PAC buscava efetivamente fazer entregas para a população, e não poderia atingir seus objetivos utilizando as engrenagens emperradas da administração pública federal.

Nosso objetivo não é analisar de forma detalhada o mecanismo de atuação do PAC, mas algumas inovações devem ser lembradas. $O$ orçamento das ações consideradas incluídas no programa não está sujeito ao contingenciamento de recursos por parte do governo, garantindo assim os meios financeiros necessários para a realização dos projetos. Posteriormente, o PAC passou a se valer do Regime Diferenciado de Contratações (RDC) para conferir maior agilidade nos processos de contratação por parte do governo. Dessa forma, a Lei $n^{0} 8.666$, que figurava como mais um dos entraves a ser vencido no caminho rumo à maior agilidade do Estado, era superada, restando à máquina pública o enfrentamento de seus problemas internos.

Um dos pontos marcantes dessa nova forma de se administrar o Estado foi a criação de instâncias decisórias efetivas no âmbito dos empreendimentos do PAC, as chamadas Salas de Situação. Nelas, as pessoas responsáveis pela execução da política nos diferentes órgãos envolvidos são reunidas em um mesmo ambiente para resolver diretamente os entraves pos- síveis e prestar contas de suas atribuições para os demais interessados. Trata-se de inovação com foco na agilidade, construindo novamente um bypass nos mecanismos tradicionais de gerenciamento das questões de governo, sabidamente contaminadas pelas clássicas disfunções da administração pública tradicional.

\section{O Monitoramento de Prioridades da Presidência da República (Governo Dilma)}

A aquisição de informações relevantes e tempestivas está no centro do caminho rumo ao aumento da qualidade das entregas de bens e serviços públicos para a sociedade. Essa afirmativa independe do regime ou da forma de governo. Seja em um contexto democrático, seja em um contexto autoritário, a qualidade dos dados coletados exerce influência determinante sobre a capacidade de o governo tomar as atitudes consideradas corretas em um dado momento histórico.

A partir dessa percepção e visando atender às necessidades de monitoramento de sua agenda de temas prioritários, o Governo Federal resolve instituir um processo de aquisição e organização de informações, junto aos ministérios executores das políticas, que subsidie a tomada de decisão em nível estratégico, mas que ao mesmo tempo esteja intimamente conectado com a realidade da implementação 
na ponta. Começa a ser estruturada junto à Presidência da República uma equipe responsável pela comunicação com os órgãos implementadores e pelo subsequente recebimento, tratamento e disponibilização dos dados finalísticos em um formato adequado.

O Gabinete Adjunto de Informações em Apoio à Decisão (Gaia) começa a ser demandado a produzir fichas informativas para o então Presidente Lula, resumidas em uma página para cada tema prioritário. Com o aumento da complexidade do conteúdo e com a valorização dessas informações pela Presidência, começa a ser editado um caderno mensal com os destaques das agendas prioritárias, congregando todas as informações recebidas no período de referência.

Já se observa aí a clara demarcação do que é prioritário para o governo, e que, portanto, deve ser acompanhado de perto, com atualização frequente das informações e manutenção de um fluxo de comunicação aberto e eficaz. Predomina a demanda por informações relacionadas a fatos concretos, mais especificamente às entregas feitas, regionalizadas por município da federação. Durante o governo do ex-presidente Lula, esse processo é mantido sem grandes alterações de forma, e sua utilização é frequente nas suas falas durante as visitas aos municípios.

Com a eleição da Presidenta Dilma Rousseff, a diagramação das fichas foi alterada para um formato que atendesse ao estilo adotado pela dirigente. As fichas passaram por uma revisão, feita pela própria Presidência, e posteriormente remetidas para o GAIA, com o objetivo de se implementar o novo modelo. Dessa maneira estava atendida a demanda por informações com o recorte territorial que subsidiasse a dirigente em discussões ou apresentações voltadas para públicos de regiões específicas.

Ainda no âmbito da Presidência da República, a Casa Civil também inicia um processo de acompanhamento do rol de políticas prioritárias com um recorte diferente do GAIA. A Subchefia de Articulação e Monitoramento assume o comando do processo e pactua com os ministérios o elenco de informações acerca da execução de cada agenda, incluindo indicadores individualizados, a serem atualizados periodicamente. Surge então mais um lugar de agregação de informações dentro da estrutura central do Executivo Federal. 


\subsection{O MONITORAMENTO DE} PRIORIDADES DA PRESIDÊNCIA E O MONITORAMENTO DO PLANO PLURIANUAL 2012-2015 NO ÂMBITO DO MINISTÉRIO DO PLANEJAMENTO

No final da Seção 1, mencionamos a sobreposição de objeto existente entre, de um lado, modelos de monitoramento mais amplo e, de outro, específicos. Vejamos como isso se aplica ao binômio de monitoramento "Prioridades da Presidência e Plano Plurianual".

O acompanhamento exercido no âmbito do PPA 2012-2015 aplica-se a todo o universo de programas do Plano. Basicamente, pede-se que as áreas fins do governo enviem, por meio do Sistema Integrado de Planejamento e Orçamento (SIOP), informações sobre a situação de execução das iniciativas, bem como a evolução no atendimento de metas e objetivos.

O Monitoramento de Prioridades lida, muitas vezes, com informações semelhantes às prestadas ao SIOP, com a diferença de que suas agendas prioritárias não necessariamente utilizam os recortes de programas do PPA, além de a frequência de atualização não se submeter aos prazos legais estabelecidos para o PPA. Para esse monitoramento específico, observa-se a tempestividade pela óptica da oferta de informações, sem esperar que sejam demandadas pelas instâncias superiores, como ocorre nos sistemas tradicionais.

O monitoramento do PPA, por razões legais, tem o compromisso de servir como plataforma à prestação de contas governamentais ao Legislativo, aos órgãos de controle e à sociedade. Aplicar suas rotinas de recepção e tratamento da informação ao leque amplo de ações governamentais que ele envolve, explica, ao menos em parte, suas limitações em processar tempestivamente o conteúdo do SIOP para a tomada de decisões estratégicas do governo.

As mudanças no formato do PPA e a instituição do SIOP, em substituição ao Sistema de Informações Gerenciais e de Planejamento (SIGPLAN), representaram uma tentativa de superar o caráter de pouca utilidade do sistema de monitoramento anterior. O objetivo é capacitar o novo sistema a funcionar como ferramenta de gestão que municie a cúpula de governo com dados suficientemente dinâmicos para promover ajustes devidos no curso das ações do poder público.

Ainda que o PPA e o SIOP se aproximem de tais fins, não se espera que os processos formais venham a suprimir a necessidade de arranjos de monitoramento específicos. A simples existência de agendas prioritárias já justifica a 
criação e manutenção de processos de acompanhamento focalizados. Além disso, os compromissos legais do monitoramento amplo e o extenso rol de políticas que ele abarca sempre reduzirão sua capacidade de atender às exigências de flexibilidade de processos e de fluxos de informação ao governante.

\subsection{O MONITORAMENTO DE PRIORIDADES DA PRESIDÊNCIA NO MINISTÉRIO DO PLANEJAMENTO, ORÇAMENTO E GESTÃO}

Diante do cenário apresentado, em que as informações relevantes passaram a ser passíveis de serem obtidas e capazes de gerar resultados positivos e concretos na condução das políticas, o MPOG decidiu fazer uso de um modelo similar ao adotado pela Presidência da República em sua prática de acompanhamento dos temas/agendas considerados por ela prioritários.

Esse monitoramento busca aproveitar a estrutura do Ministério, com as especificidades de cada secretaria, para criar uma rede interna de troca e complementação de informações sobre a participação (atual ou potencial) do Órgão no andamento dos temas prioritários. Busca-se, principalmente, a detecção de entraves ou fragilidades sobre as quais o Ministério tem, institucionalmente, condições de atuar, como a disponibilida- de de recursos orçamentários e de pessoal, questões ligadas a patrimônio da União e tecnologias da informação, dentre outros. 0 propósito final, portanto, é fundamentar as decisões estratégicas de alocação de recursos e esforços do Órgão para esses recortes selecionados de políticas.

Para a produção e troca das informações, desenhou-se um arranjo em que todas as secretarias do Ministério participam no preenchimento de Fichas Situacionais referentes às atividades de sua competência em qualquer dos temas prioritários. Há, porém, para cada tema, uma secretaria que atua como ponto focal - instância agregadora das informações geradas em todo o Ministério -, posto a ser ocupado pela secretaria com maior participação, maior protagonismo, em cada agenda, conforme lista de exemplos no Anexo I.

Uma vez que cada secretaria tenha agregado as informações dos temas sob sua responsabilidade, os documentos são enviados para a Secretaria-Executiva do MPOG para consolidação final de todas as agendas, antes dispersas pelas pastas do Ministério. Ao final, é produzido o Relatório de Situação, idealmente mensal, com o intuito de fornecer informações úteis sobre o andamento das políticas e subsidiar decisões estratégicas do Ministério em cada caso. Importante lembrar que, apesar de o relatório ter essa periodicidade, a atua-

Revista Brasileira de Monitoramento e Avaliação | Número 5 | Janeiro-Junho de 2013 
lização das informações por parte dos analistas se dá constantemente. Dessa maneira, a prática atual aproxima-se do modelo que opera pela lógica da oferta de dados relevantes, superando o paradigma do fornecimento de informações acoplado às datas ou à periodicidade determinada pelos demandantes.

\subsection{O MONITORAMENTO DAS} PRIORIDADES DA PRESIDÊNCIA NA SECRETARIA DE PLANEJAMENTO E INVESTIMENTOS ESTRATÉGICOS (SPI) DO MINISTÉRIO DO PLANEJAMENTO, ORÇAMENTO E GESTÃO

A Secretaria de Planejamento e Investimentos Estratégicos (SPI) insere-se no processo acima descrito como ponto focal atualmente de 19 dos 39 temas prioritários, estando a maioria dos demais sob responsabilidade da Secretaria do Programa de Aceleração do Crescimento, já que compreendem ações do PAC.

Internamente à SPI, as rotinas foram organizadas de maneira que, idealmente a cada mês, os departamentos finalísticos responsáveis pelo preenchimento das fichas situacionais as atualizem. Todas as fichas são então enviadas para uma instância agregadora, que se convencionou chamar de Sala do PPA, responsável pela conferência geral e preparação do documento consolidado. Reuniões regulares são feitas dentro da SPI, envolvendo sempre alguns de seus altos dirigentes, gerentes, coordenadores e os próprios analistas, com vistas a que todos possam intei- rar-se acerca do andamento das agendas, e, assim, qualificar seus posicionamentos em reuniões de alto escalão dentro ou fora do Ministério. Com o tempo, percebeu-se na SPI que a Ficha Situacional não possuía um formato gerencial adequado para leitura e compreensão rápida de seu conteúdo mais relevante. Ela continha campos extensos, cujos conteúdos pareciam se repetir mês a mês. Com isso, dificultava-se a transmissão das informações realmente úteis às instâncias decisórias, tais como necessidades, restrições e problemas de implementação da política, baixando-se com isso a motivação dos próprios preenchedores das fichas. A Sala do PPA propôs internamente à SPI criar-se um formulário que, à parte da Ficha Situacional, destacaria as informações mais imediatas e dinâmicas para as decisões superiores do Órgão. Ele entraria na rotina de atualização empreendida pelos analistas preenchedores, e, ao final do processo, a Sala do PPA elaboraria um Caderno Mensal, em que reuniria os destaques de cada agenda prioritária. Juntamente com essa iniciativa, criou-se uma plataforma intranet para facilitar a transmissão das informações e automatizar a elaboração dos cadernos consolidados.

Essa dinâmica de adaptações e aperfeiçoamentos nas rotinas internas encontra-se ainda em fase de testes e novos ajustes, situação típica - porém desgastante - de processos inovadores como este, ainda um embrião de nova cultura e prática de monitoramento de temas prioritários de governo. 


\section{Desafios}

Acerca das dificuldades, mencionadas na seção anterior, para criação de uma rotina de fornecimento de informações que seja sustentável, dinâmica e capaz de convergir para um relatório gerencial que subsidie decisões estratégicas, pode-se afirmar que o sucesso do modelo depende de aprimoramentos de tipo horizontal e vertical dentro do Ministério do Planejamento.

Do ponto de vista horizontal, o modelo requer maior integração entre as secretarias do Ministério. Do ponto de vista vertical, ele necessita de maior feedback dos decisores às instâncias operacionais do processo quanto às informações que recebem nas Fichas.

Em suma, pode-se dizer que a eficácia do processo está condicionada a uma maior integração entre todos os atores envolvidos nas etapas de levantamento, tratamento e utilização da informação. Essa integração tende a promover o comprometimento das áreas relacionadas ao levantamento das informações. Por isso, um desafio a este tipo de trabalho é, portanto, promover uma cultura de maior diálogo no arranjo intrainstitucional estabelecido entre as diversas instâncias que participam do monitoramento de temas prioritários.

Por fim, qualquer modelo de monitoramento na esfera pública enfrenta um desafio intrín- seco, já que o processo de obtenção de informações a respeito de ações de governo é complexo, sensível e difícil de ser padronizado. Revelar fraquezas não faz parte da cultura política e administrativa brasileira, e o monitoramento não pode existir somente para divulgar sucessos das políticas implementadas. Os limites da eficácia de um monitoramento de prioridades já sofrem com o inevitável viés de curto prazo dos efeitos das intervenções sobre as agendas. Para reduzir os efeitos das dificuldades em obtenção de informação, a percepção de utilidade a partir do processo é vital. Espera-se que, com o contínuo esforço e aperfeiçoamento dos mecanismos e produtos envolvidos nesse processo, seja disseminada pela administração pública a cultura da cooperação através do compartilhamento de informações relevantes, e que consolidem-se tais práticas como básicas no caminho para o aperfeiçoamento da gestão de governo.

\section{Conclusões}

A volta do planejamento como ferramenta vital para a boa atuação de um Estado promotor do desenvolvimento e do bem-estar social trouxe a necessidade de se instituírem mecanismos adequados de monitoramento das políticas públicas. Essa emergência do planejamento mostrou que a atividade de acompanhamento das ações de Estado vai muito além da simples mensuração da execução física ou financeira do orçamento. 
Trata-se de processo multifacetado, transversal a diversos órgãos e que deve levar em consideração, necessariamente, os arranjos formados interna e externamente à agenda avaliada para que se possa explicar seu andamento e, ainda, o porquê de algumas metas não estarem sendo alcançadas. A compreensão de cada ator envolvido na política acerca de como operam esses arranjos, assim como de sua inserção neles, impulsionaria o processo de aprendizagem e difusão de conhecimento, essenciais à melhoria da gestão pública. Tudo isso sempre com foco no auxílio à implementação para a melhoria das entregas feitas ao povo.

Nessa trajetória governamental de reinvenção do monitoramento, algumas tentativas se mostraram insuficientes, como a construção do Sistema de Informações Gerenciais e de Planejamento (SIGPLAN), âncora do monitoramento do PPA até 2011. Suas limitações justificaram, em parte, a criação de rotinas diferenciadas para que o governo central possa obter as informações desejadas, em tempo hábil, acerca da execução das políticas eleitas como prioritárias pela Presidência da República. No entanto, conforme tentamos evidenciar no texto, o argumento central para a adoção desse monitoramento é a própria existência política de um grupo especial de agendas, representativas do projeto de governo do presidente eleito.

O sucesso na implementação dessas agendas terá influência significativa sobre o grau de 
aprovação popular do mandato do governante, e daí a focalização de esforços no monitoramento da execução delas. Esse modelo de acompanhamento, portanto, se justifica em si mesmo, ainda que opere em certa sobreposição com outros sistemas formais já existentes.

Mostramos, também, que a concepção de monitoramento como aprendizado não impede a legítima coexistência de sistemas de acompanhamento que se prestem a dar soluções mais urgentes para os problemas iminentes de determinadas políticas, consideradas prioritárias pelo governante eleito. Defendemos que esse modelo, a despeito de suas limitações intrínsecas, algumas delas exploradas na Seção 2, tem forte base de legitimação política e é capaz de trazer melhorias concretas à gestão pública.

O modelo de gestão e monitoramento prioritário do PAC, conforme mencionamos na Subseção 4.2, alavancou a capacidade do governo para entregar bens e serviços à sociedade, por meio de institucionalidade alternativa - mais dinâmica e flexível. Sem desconsiderar uma gama certamente não desprezível de novos problemas e questões trazidas à baila por esta experiência, o certo é que os êxitos até o momento contabilizados vêm inspirando arranjos de gestão e monitoramento semelhantes, em que experimentalismos e aprendizados vêm instigando e contribuindo para o próprio fortalecimento institucional do Estado no Brasil. 
CHAVES, M. B. F. Sistema de apoio ao monitoramento das metas presidenciais. In: IX Congreso Internacional del CLAD sobre la Reforma del Estado y de la Administración Pública, Madrid, España, 2004.

MARTINS, H. F. Sistema de Monitoramento do Plano Plurianual, Sistema de Monitoramento de Metas Presidenciais, Sistema de Monitoramento e Avaliação de Políticas e Programas Sociais, Sistema de Avaliação Externa de Programas Governamentais, Brasil. In: BANCO MUNDIAL. Fortalecimiento de los sistemas de monitoreo y evaluación (M\&E) en América Latina.Centro Latinoamericano de Administración para el Desarrollo (CLAD), 2007.

MELO, E. B. B e Rodrigues, R. W. S. Monitoramento, Avaliação e Controle - Superando o debate técnico burocrático.V CONSAD, Brasília, 2012.

BRASIL. Ministério do Planejamento, Orçamento e Gestão. Plano Mais Brasil: Plano Plurianual 2012-2015. Secretaria de Planejamento e Investimentos Estratégicos, Brasília, 2011.

BRASIL. Ministério do Planejamento, Orçamento e Gestão. Mensagem Presidencial do Plano Plurianual 2012-2015. Secretaria de Planejamento e Investimentos Estratégicos, Brasília, 2011.

MORETTI, B.O Planejamento Governamental como Discurso: Tensões entre Política e Técnica (1930-2003), Tese de doutorado apresentada ao departamento de Sociologia UNB, Brasília, 2012.

MULLER, P. SUREL Y.A Análise das Políticas Públicas. EDUCAT, Pelotas, 2002.
NADER, R. M. A avaliação como ferramenta para uma gestão pública orientada para resultados. O caso do Governo Federal Brasileiro. Estudo para o CLAD, 2005.

PEREIRA, P. A. P. A Intersetorialidade das políticas sociais em uma perspectiva dialética.Brasília: UnB, 2011.

PIRES, R. et al., Métodos qualitativos de avaliação e suas contribuições para o aprimoramento de políticas pública. In: Brasil em Desenvolvimento : Estado, planejamento e políticas públicas. Brasília:Instituto de Pesquisa Econômica Aplicada, Parte V, 2010.

BRASIL. Presidência da República. Decreto $\mathrm{n}^{\circ}$ 7.866, de 19 de dezembro de 2012, regulamenta a gestão do Plano Plurianual 2012-2015. Casa Civil, 2012.

PRESSMAN, J. L;WILDAVSKY, A. Implementación. Cómo grandes expectativas concebidas em Washington se frustran em Oakland. México: Fondo de Cultura Económica, 1998.

SANTOS, B. de S. Um discurso sobre as ciências na transição para uma ciência pós-moderna. Estudos avançados. São Paulo: Fapesp, 1988.

SCHNEIDER, A. L. Pesquisa avaliativa e melhoria da decisão política: evolução histórica e guia prático. In: POLÍTICAS públicas e desenvolvimento: bases epistemológicas e modelos de análise. Brasília: Editora UnB, 2006.

SOUZA, C. Políticas Públicas: uma revisão de literatura. Rev. Sociologias, Porto Alegre, 2006. 


\section{- ANEXO I: AGENDAS PRIORITÁRIAS PARA O GOVERNO DILMA (LISTA MUTÁVEL), AGRUPADAS SEGUNDO EIXO ESTRATÉGICO.}

\begin{tabular}{|c|c|}
\hline EIXOS & AGENDAS PRIORITÁRIAS \\
\hline \multirow{3}{*}{ Redução da Pobreza e Superação da Miséria } & Brasil Sem Miséria \\
\hline & Microcrédito \\
\hline & Territórios da Cidadania \\
\hline \multirow{5}{*}{ Infraestrutura para o Desenvolvimento } & Marco Regulatório Portuário \\
\hline & Marco Regulatório Ferroviário \\
\hline & Marco Regulatório Aeroportuário \\
\hline & Prevenção a desastres naturais \\
\hline & Minha Casa, Minha Vida \\
\hline \multirow{6}{*}{ Melhoria da Saúde da População } & Mama e colo do útero \\
\hline & SOS Emergências \\
\hline & Rede Cegonha \\
\hline & Melhor em Casa \\
\hline & UPA \\
\hline & UBS \\
\hline \multirow{5}{*}{$\begin{array}{l}\text { Educação como instrumento de desenvolvi- } \\
\text { mento e inclusão social }\end{array}$} & Creches \\
\hline & PRONATEC \\
\hline & Ciência sem Fronteiras \\
\hline & Prova Brasil (educação básica) \\
\hline & ENEM \\
\hline \multirow{4}{*}{ Segurança e Enfrentamento às Drogas } & Cadeias Públicas \\
\hline & Plano Estratégico de Fronteiras \\
\hline & Crack, é Possível Vencer \\
\hline & Plano Nacional de Segurança Pública \\
\hline \multirow{3}{*}{ Cidadania } & Viver sem Limite \\
\hline & Enfrentamento da Violência no Trânsito \\
\hline & Brasil Protege: Enfrentamento da Violência contra Criança e Adolescente \\
\hline \multirow{5}{*}{ Estabilidade e Desenvolvimento Econômico } & Brasil Maior \\
\hline & Agricultura (Insumos, Plano Safra e Armazenagem) \\
\hline & Regularização Fundiária \\
\hline & Marco Regulatório da Mineração \\
\hline & Base Industrial de Defesa \\
\hline \multirow{4}{*}{ Comunicações e Tecnologia } & Banda Larga \\
\hline & Satélite Geoestacionário \\
\hline & Regulação das Teles \\
\hline & Financiamento à Inovação Tecnológica \\
\hline \multirow{2}{*}{ Meio Ambiente e Sustentabilidade } & Mudanças Climáticas \\
\hline & Controle do Desmatamento \\
\hline Gestão, Desempenho e Competitividade & Câmara de Gestão \\
\hline \multirow{2}{*}{ Grandes Eventos } & Copa 2014 \\
\hline & Olimpíadas \\
\hline
\end{tabular}

Revista Brasileira de Monitoramento e Avaliação | Número 5 | Janeiro-Junho de 2013 